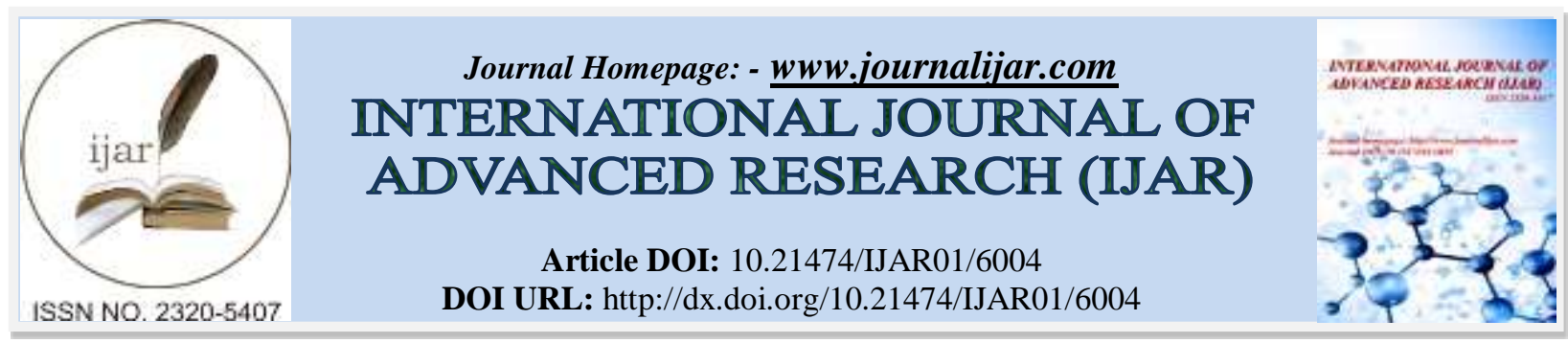

RESEARCH ARTICLE

\title{
KAPOSI'S SARCOMA IN PATIENT UNDERGOING DIALYSIS AFTER TREATMENT OF LUPUS NEPHRITIS: A CASE REPORT.
}

Mohamed Reda El Farouki ${ }^{1}$ and Mohamed Hassani ${ }^{2}$.

1. Doctor, Nephrology department, Moulay Ismail Military Hospital, Meknes, Morocco.

2. Professor, Nephrology department, Moulay Ismail Military Hospital, Meknes, Morocco.

\section{Manuscript Info}

Manuscript History

Received: 08 October 2017

Final Accepted: 10 November 2017

Published: December 2017

Key words:-

Kaposi sarcoma; hemodialysis; lymph nodes; lupus nephritis.

\begin{abstract}
Kaposi's Sarcoma (KS) is a low-grade vascular tumor that derived from lymphatic endothelial cells infected with type 8 of human herpes virus (HHV8) also known as Kaposi Sarcoma associated herpesvirus (KSHV). Iatrogenic form of KS is most often detected in patients after kidney transplantation which reflects the higher frequency in this population. KSis most notable for its cutaneous involvement, characterized by dermal purplish, reddish blue, or dark black macules, plaques, and nodules. Lymph node enlargement and visceral localization are other clinical manifestation of KS. Visceral involvement occurs in 25 to 30 percent of patients with kidney transplants and in 50 percent of those with liver or heart transplants. We present a 46-year-old man undergoing dialysis due to lupus nephritis, with multiple lymph nodes who had biopsy-proven KS.
\end{abstract}

Copy Right, IJAR, 2017,. All rights reserved.

\section{Introduction:-}

Kaposi's sarcoma (KS) was described for the first time by Moritz Kaposi in 1872, acquiring subsequently a particular interest in being a tumor in patients with AIDS. In 1994, Human herpesvirus type 8 (HHV-8) was discovered and classified in the family of gammaherpesvirus. It has been universally isolated in all variants of Kaposi's sarcoma. Although haemodialysis patients have been found to be more susceptible to viral infections, such as HHV-8, and hence in danger of developing KS, the connection between dialysis, HHV-8, and KS is not yet well established. In this report, a case of Kaposi's sarcoma in a chronic hemodialysis patient HIV(-) will be described.

\section{Case Report:-}

A 46- year-old man (in the final stages of renal failure/ dysfunction) with end-stage-renal-disease due to lupus nephritis class IV, under corticosteroids for one year and has also received cyclophosphamide, been taking hemodialysis three times a week for 04 months. A weight loss has been noticed for two months, concomittent with resistance to ASE. His clinical examination showed left atrial and right inguinal lymphadenopathy, as well as a scrotal purple papule. There was not any abnormal finding in other physical examination. The haematological investigations revealed haemoglobin $10 \mathrm{~g} / \mathrm{dl}$, WBC $9300 / \mathrm{mm}^{3}$, platelet $250.000 / \mathrm{mm}^{3}$, and C reactive protein 50 $\mathrm{mg} / \mathrm{l}$. Serological test for HIV was negative. Chest, abdominal and pelvic CT scan showed right axillary, and left inguinal lymphadenopathy. Biopsy of the retro-auricular nodule and the left adenopathy showed vascular spaces in the form of slits with extravasated erythrocytes and proliferating pleomorphic spindle- shaped cells. Immunohistochemical stainings for CD3, AE1/AE3, AML and PS100 were performed. Positivity of anti-CD3 with spindle-shaped cells was observed. Anti-HHV8 was also positive in the cell nucleus of the tumoral cells confirming 
the diagnosis of KS (Figures 1, $2 \&$ 3). Treatment consisted of a rapid depression of steroids until they stop, accompanied by a disappearance of the macules and the clinical and radiological lymphadenopathies as well as a weight gain.

\section{Discussion:-}

KS is caused by human herpesvirus 8 infection and can occur in patients with advanced immunosuppression (the iatrogenic form: after transplant organs particularly for renal and hepatic transplant or epidemic form, e.g., due to HIV infection), in patients of Mediterranean, Eastern European, or Middle Eastern descent (the classic form), or in patients living in equatorial Africa (the endemic form). [1-3]

HHV-8 is transmitted predominantly through saliva. It's a complex DNA virus and infection which leads to cell morphology changes, growth rate and extended life span, and provokes deregulated angiogenesis, inflammation and modulation of immune system encouraging tumor growth [4].

HIV testing was negative in our patient. Intensive immunosuppressive therapy is significantly associated with higher risk of developing KS after transplantation [2]. The rate of post-transplantation KS was estimated at about $0.5 \%$ [5]. KS is rarely described in chronic hemodialysis and after treatment of lupus nephritis.

It can be manifested by purple erythematous plaques and nodules, similar to those seen in our patient. Visceral localization such as lymph node, uterine cervix, gum, tonsils, lung and heart were also described [6]. Our patient has skin and lymph node localization.

The HHV-8 represents the principal causative agent of KS. It may be complicated by lymphedema or hyperkeratosis. Histologically, multicentric neoformation of atypical lymphatics represents the primary process in histogenesis of CKS. Patch-stage KS, the earliest pattern, typically arises in the reticular dermis as a clinically macular lesion. A proliferation of small, irregular and jagged endothelium lined spaces surrounding normal dermal vessels and adenexal structures accompanied by a variable, inflammatory lymphocytic infiltrate (with or without plasma cells) is characterized [7]. Plaque-stage KS, the histological correlate of small palpable lesions, represents the expansion of a spindle cell vascular process throughout the entire dermis at times extending to the subcutaneous fat. Nodular-stage KS lesions are composed of sheets and fascicles of spindle cells with mild to moderate cytological atypia, single cell necrosis, and trapped erythrocytes within an extensive network of slit-like vascular spaces. Vessels lack a prominent investment of pericytes and have a fragmented basal lamina and frequent discontinuities in the endothelial lining [7].

Reduction or withdrawal of immunosuppressive therapy caused complete remission of KS in most patients [8]. The conversion of calcineurin inhibitors such as Cyclosporine or Tacrolimus to Sirolimus (because of antiproliferative properties) is the most effective treatment [9-10].

For patients who do not respond, the choice of therapy with a second-line agent (vinblastin alone or in combination with bleomycin, paclitaxel, oral etoposide, and gemcitabine) must be individualized.

\section{Conclusion:-}

In this case we described an unusually KS with lymph nodes and skin involvement. According to our knowledge, the report of disseminated KS is common in AIDS, but it is rare after treatment of lupus nephritis and in chronic hemodialysis.

\section{Financial support and sponsorship: Nil.}

\section{Conflicts of interest:}

There are no conflicts of interest. 
Figure 1:- Slit like vascular spaces and proliferation of atypical spindle cells (Haematoxylin and eosin staining, original magnification $\mathrm{x} 10$ )

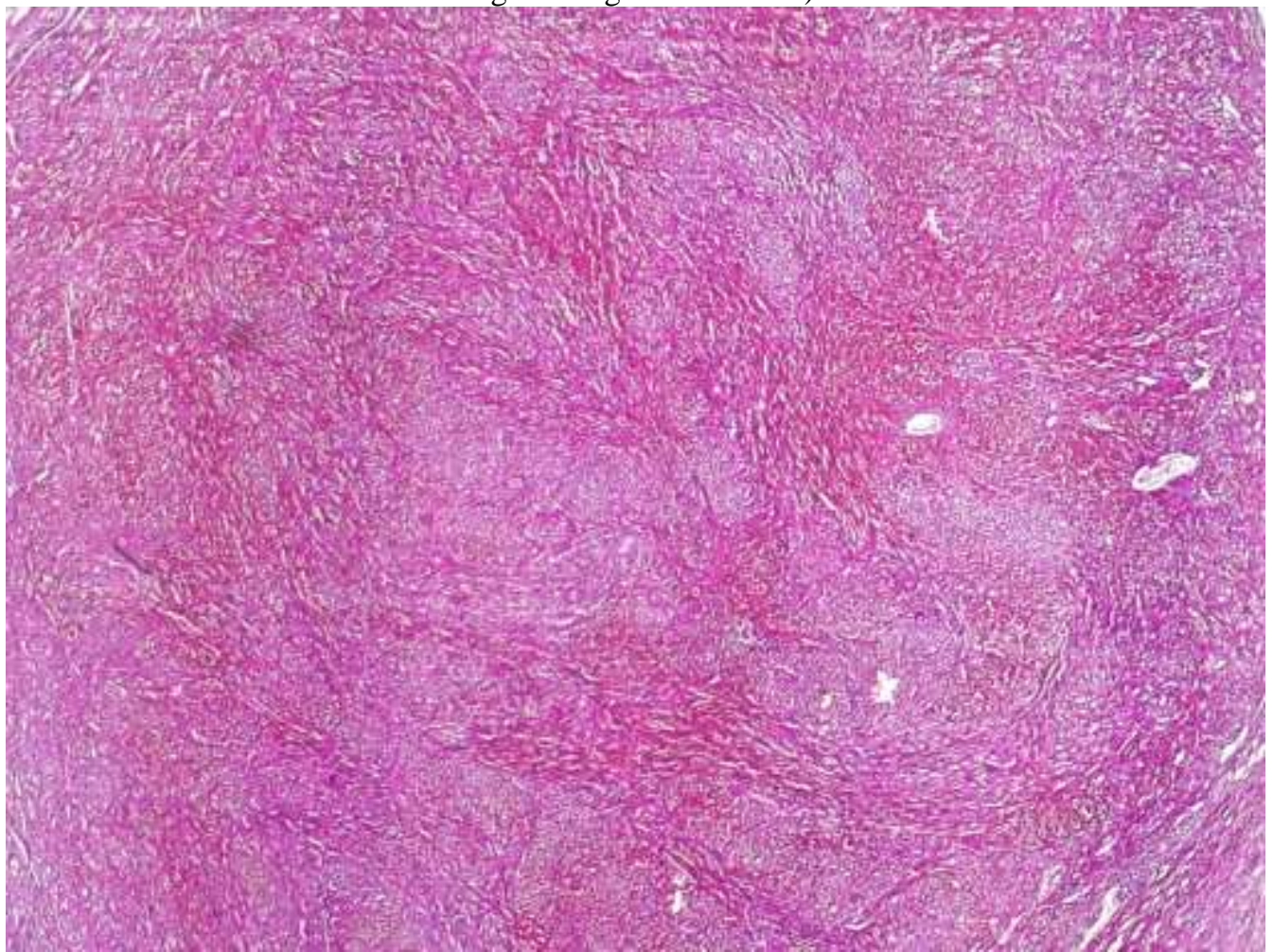

Figure 2:- Vascular spaces in the form of slits with extravasated erythrocytes and proliferating pleomorphic spindle shaped cells (Haematoxylin and eosin staining, original magnification $\mathrm{x} 40$ ).

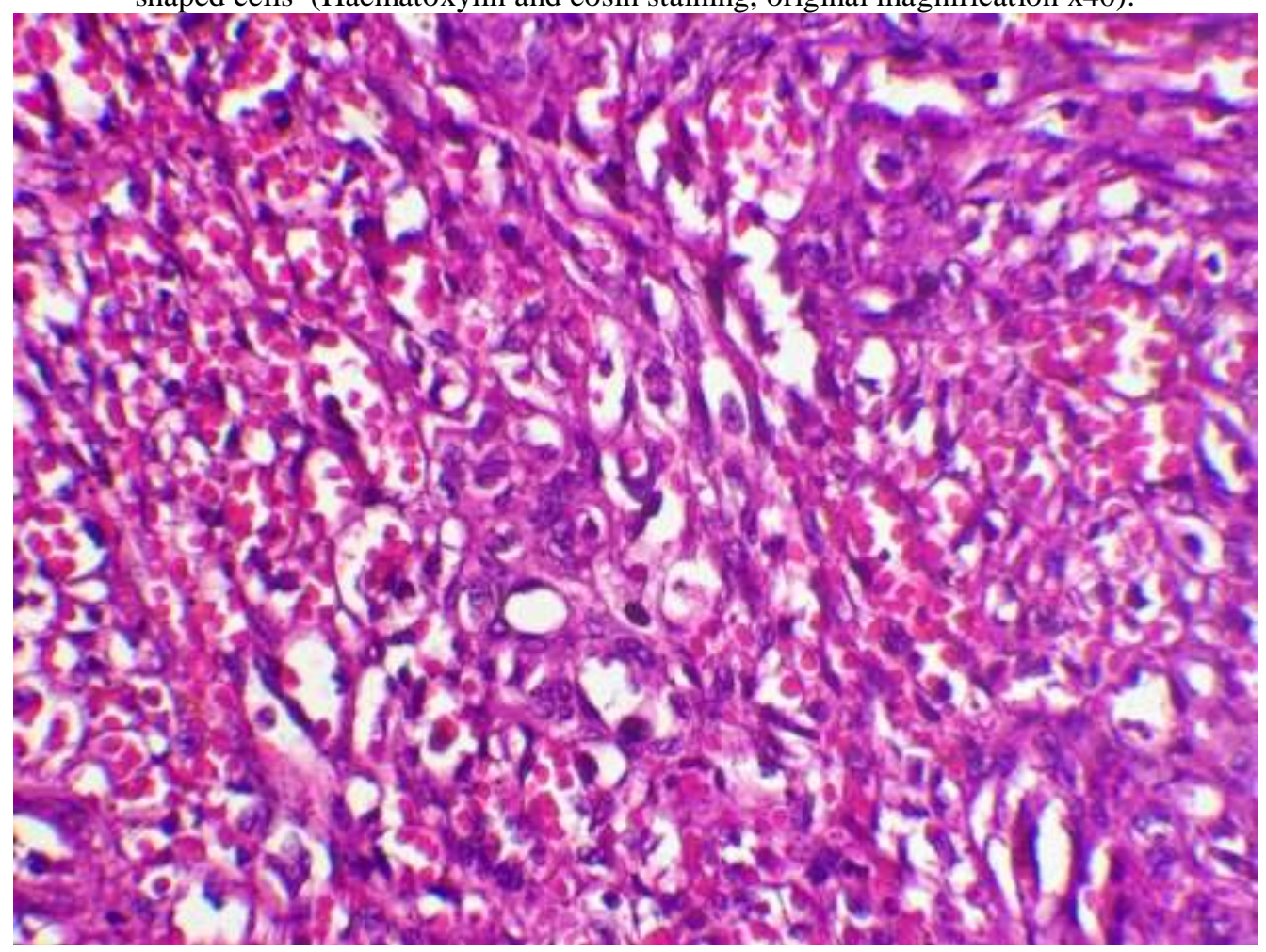


Figure 3:- Expression of HHV-8 by the tumour cells (Immunohistochemical study).

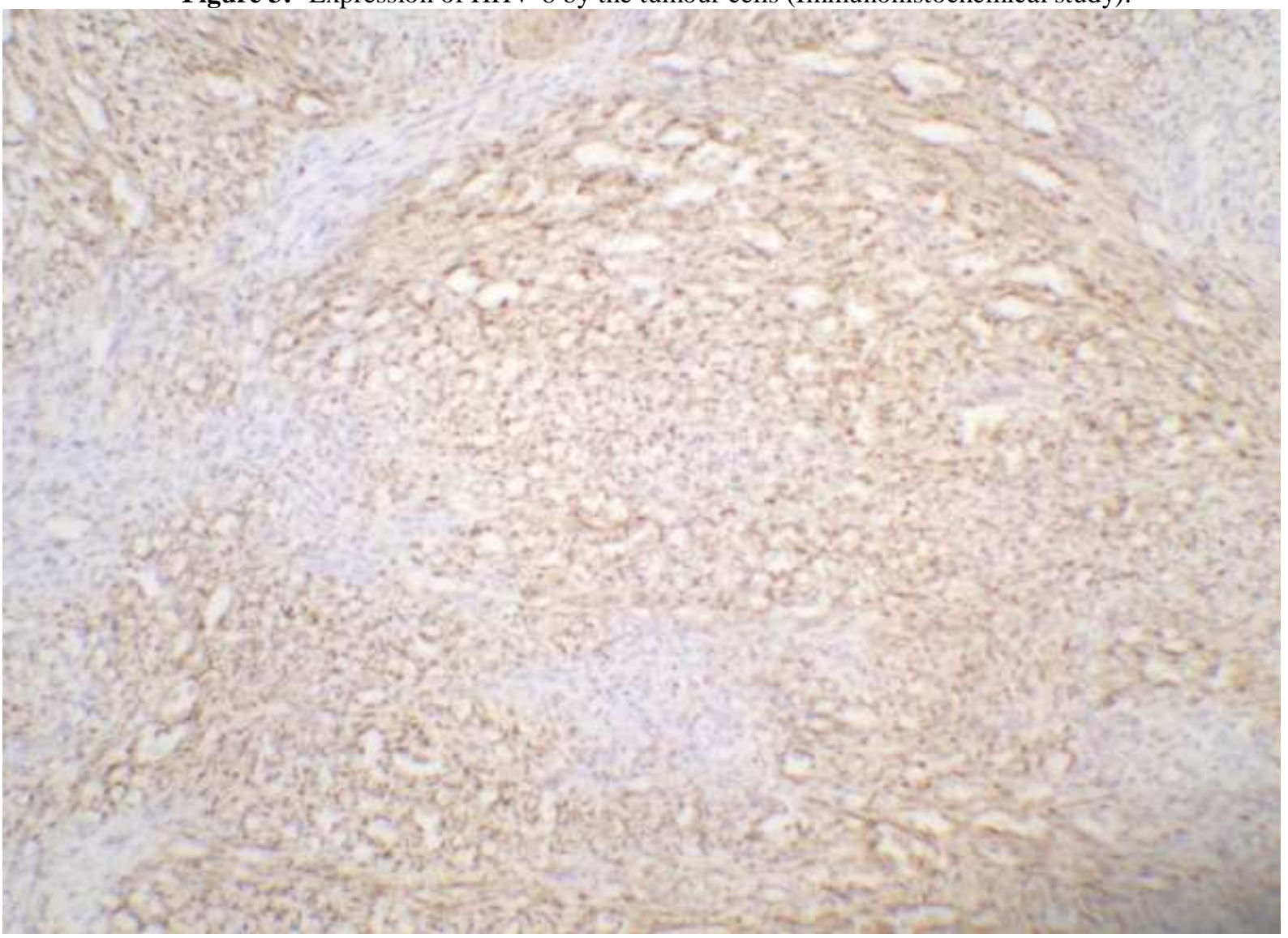

\section{References:-}

1. Pietti WW. The incidence of secong malignancies in subsets of Kaposi's sarcoma. J Am Acad Dermatol 1987; 16: 855-61

2. Penn I. The changing patterns of posttransplant malignancies. Transplant proc 1991; 23: 1101-3

3. Beral V. Epidemiology of Kaposi's sarcoma. In: Franks LM, eds: Cancer surveys. New York: Cold Spring Harber Lab Press, 1991; 5

4. Hengge UR, Ruzicka T, Tyring SK, et al. Update on Kaposi's sarcoma and other HHV8 associated diseases. Part 1: epidemiology, environmental predispositions, clinical manifestations, and therapy. Lancet Infect Dis $2002 ; 2: 281-92$

5. Euvrard S, Kanitakis J, Claudy A. Skin cancers after organ transplantation. N Engl J Med. 2003; 348(17): 1681 $-1691$

6. Einollahi B. Unusual site of Kaposi sarcoma after kidney transplantation. Iranian Journal of Kidney Diseases. 2012; 6(3): $164-165$

7. Cai Q, Verma SC, Lu J, Robertson ES. Robertson molecular biology of Kaposi's sarcoma-associated herpesvirus and related oncogenesis. Adv Virus Res $2010 ; 78: 87-142$

8. Costa Ferreira P, Miguel Pereira J, Oliveira I, Pinho C, Cardoso A, Reis J, et al. Unusual Kaposi's sarcoma in a renal transplant recipient. Nephrol Dial Transplant. 2005; 20(12): 2830 - 2831

9. Charfi S, Krichen-Makni S, Yaich S, Makni H, Khabir A, Amouri A, et al. Successful treatment of post-renal transplant gastric and pulmonary Kaposi's sarcoma with conversion to rapamycin treatment. Saudi J Kidney Dis Transpl. 2007; 18(4): $617-620$

10. Campistol JM, Schena FP. Kaposi's sarcoma in renal transplant recipients-- the impact of proliferation signal inhibitors. Nephrol Dial Transplant. 2007; 22(Suppl 1): i17 - i22 